\title{
Dead or alive? Comparing costs and benefits of lethal and non-lethal human-wildlife conflict mitigation on livestock farms
}

\author{
J. S. McManus, A. J. Dickman, D. Gaynor, B. H. Smuts and D. W. Macdonald
}

\begin{abstract}
Livestock depredation has implications for conservation and agronomy; it can be costly for farmers and can prompt retaliatory killing of carnivores. Lethal control measures are readily available and are reportedly perceived to be cheaper, more practical and more effective than nonlethal methods. However, the costs and efficacy of lethal vs non-lethal approaches have rarely been compared formally. We conducted a 3-year study on 11 South African livestock farms, examining costs and benefits of lethal and non-lethal conflict mitigation methods. Farmers used existing lethal control in the first year and switched to guardian animals (dogs Canis familiaris and alpacas Lama pacos) or livestock protection collars for the following 2 years. During the first year the mean cost of livestock protection was USD 3.30 per head of stock and the mean cost of depredation was USD 20.11 per head of stock. In the first year of non-lethal control the combined implementation and running costs were similar to those of lethal control (USD 3.08 per head). However, the mean cost of depredation decreased by $69.3 \%$, to USD 6.52 per head. In the second year of non-lethal control the running costs (USD 0.43 per head) were significantly lower than in previous years and depredation costs decreased further, to USD 5.49 per head. Our results suggest that non-lethal methods of human-wildlife conflict mitigation can reduce depredation and can be economically advantageous compared to lethal methods of predator control.
\end{abstract}

Keywords Carnivore conservation, conflict mitigation, human-wildlife conflict, lethal control, livestock depredation, non-lethal mitigation techniques, profit/loss ratio

This paper contains supplementary material that can be found online at http://journals.cambridge.org

J.S. MCMANus* (Corresponding author) Centre for African Ecology, School of Animal, Plant and Environmental Sciences, University of Witwatersrand, Private Bag 3, Johannesburg 2050, South Africa

E-mail jeannine_mcmanus@hotmail.com

A.J. Dickman and D.W. MaCdonald WildCRU, Department of Zoology, University of Oxford, UK

D. GAYNOR Mammal Research Institute, University of Pretoria, South Africa

B.H. SMUTS Landmark Foundation Trust, Riversdale, South Africa

*Also at: Landmark Foundation Trust, PO Box 22, Riversdale 6677, South Africa

Received 5 June 2013. Revision requested 8 October 2013.

Accepted 27 November 2013. First published online 30 April 2014.

\section{Introduction}

epredation of livestock is a principal cause of humanwildlife conflict (Sillero-Zubiri \& Laurenson, 2001). It incurs high costs for livestock-keepers and provokes both retaliatory and preventative killing of carnivores, which may threaten their survival locally or globally (Kruuk, 2002; Ray et al., 2005; Macdonald et al., 2013). Pastoralists in the Serengeti have reported that the cost of depredation amounts to c. $19 \%$ of their annual cash income (Holmern et al., 2007), and in Bhutan attacks on livestock by carnivores cost farmers over two-thirds of their annual cash income, on average (Wang \& Macdonald, 2006). In the USA the annual cost of depredation to the livestock industry is USD 40 million (Conner et al., 2008). Even greater losses are reported in South Africa, where a survey in 2010 estimated that the annual cost of depredation to the livestock industry is USD 171 million (van Niekerk, 2010), although a 2007 census estimated the cost to be USD 22 million (Statistics South Africa, 2010). The disparity between these two estimates raises uncertainty as to their accuracy but both reveal a perception that losses to carnivores are high.

Ideally tools for reducing depredation should benefit both farmers and wildlife conservation. Desirable features of interventions include persistent efficacy, minimal unintended environmental consequences, selectivity towards problematic individuals, lower cost than that of the depredation prevented, and social acceptability. Traditionally farmers have attempted to prevent depredation, or retaliate, by killing predators (Hone, 1994; Macdonald et al., 2010), often with negative effects on carnivore populations (SilleroZubiri \& Laurenson, 2001; Woodroffe et al., 2005; Loveridge et al., 2010). In South Africa, encouraged by the government, farmers have employed lethal control of predators, using methods such as gin-traps (leg-hold traps), gun-traps, poison and hunting, with and without hounds, to eradicate carnivores and other problem animals (Daly et al., 2006). As recently as the 1990s formal bounty systems were in place for most of the terrestrial mammal species that were perceived to cause conflicts with commercial agriculture, and lethal control is still common on livestock farms (Daly et al., 2006). Despite these measures depredation remains a problem in the livestock farming sector, with indications that losses are increasing (Avenant \& du Plessis, 2008).

Lethal control is often considered the cheapest and most effective method of reducing depredation (Conover, 2001; Mitchell et al., 2004) but it is not without problems: it may 
miss problem individuals and it often fails to eradicate depredation (Avenant \& du Plessis, 2008) and involves ongoing commitment and expense (Conover, 2001; Mitchell et al., 2004). It is commonly unselective and there is little evidence of cost-effective diminution of livestock losses (Treves \& Naughton-Treves, 2005; Berger, 2006), as predators learn to avoid control efforts (Brand et al., 1995; Knowlton et al., 1999). Methods such as leg-hold traps, snaring and poisoning are largely indiscriminate and often kill non-target species (Rochlitz et al., 2010); in South Africa, this includes threatened species such as Cape vultures Gyps coprotheres (Bamford et al., 2007). Unintended outcomes of removing territorial predators can include an influx of replacement individuals, potentially increasing the local predator population and the risk of depredation (Crooks \& Soulé, 1999; Knowlton et al., 1999), through what are known generically as perturbation effects (Tuyttens \& Macdonald, 2000). Furthermore, lethal control has led to the extermination of populations of large carnivores (Kruuk, 2002), resulting in debates amongst conservationists, farmers and the general public (Treves \& Karanth, 2003; Graham et al., 2005).

The inadequacies of lethal control methods have focused attention on possible non-lethal interventions. One advantage of non-lethal control for territorial species is that it does not cause social perturbation in the way that lethal control can do; instead, the target individual is allowed to remain in its territory and although its behaviour may be altered (e.g. in the case of learned food aversions) other ecological relationships remain intact, including exclusion of potentially invading conspecifics (Reynolds, 1999). Possible nonlethal interventions include corralling livestock during periods of vulnerability (Schiess-Meier et al., 2007), installing predator-proof fencing around small vulnerable areas (Breitenmoser et al., 2005), using shepherds (Shivik, 2006), installing fladry (Davidson-Nelson \& Gehring, 2010), translocating species (Bradley et al., 2005) and using conditioned taste aversion (Cox et al., 2004), other learned food aversions (Macdonald \& Baker, 2004; Baker et al., 2008) or odour (Atkinson \& Macdonald, 1994), chemical, visual or acoustic repellents (Mason et al., 2001). Guardian animals, particularly livestock guardian dogs, are another popular method and have been found to decrease depredation by $10-100 \%$ on ranches in the USA (Linhart et al., 1979; Coppinger et al., 1988; Andelt \& Hopper, 2000; Gehring et al., 2010). They have also proved effective in southern Africa: in Namibia, $73 \%$ of farmers who used guardian dogs reported a significant decline in livestock depredation (Marker et al., 2005, 2010). Other guardian animals that behave aggressively towards stock-predators can also be effective, such as donkeys Equus africanus asinus, alpacas Lama pacos and llamas Lama glama (Conover, 2001). A promising but largely untested technique is the use of protective collars made of a strong epoxy-metal mesh.
Carnivores typically kill their prey by a fatal bite to the neck, and these collars protect the vulnerable neck area, increase the effort needed by predators to kill livestock, and reduce the likelihood of a fatal bite.

Such methods have the potential to be more selective than lethal predator control, targeting only those animals attempting to kill livestock. There is evidence that nonlethal interventions can reduce depredation (Breitenmoser et al., 2005), with the added benefits of favourable public perception, improved animal welfare and reduced nontarget casualties (Treves \& Naughton-Treves, 2005). Nonlethal methods may be more compatible with conservation objectives and less likely to trigger perturbation effects, including counter-productive ecological cascades such as mesopredator release (Beasom, 1974; Crooks \& Soulé, 1999). However, some controls can have negative consequences: from the early 1900 s to the 1960s most farms in South Africa were fenced to prevent depredation (Beinart, 2008) but fencing large areas may restrict the movement of wildlife (Knowlton et al., 1999). Livestock guardian dogs may attack wildlife if not properly managed (Green et al., 1984). Furthermore, although comprehensive audits are few, nonlethal mitigation techniques are sometimes considered more expensive (Mitchell et al., 2004) and less long-lasting than lethal predator control (Shivik, 2006). There is a dearth of rigorous accounting of the full life-cycle costs and benefits of alternative interventions. Here we assess the efficacy and economics of lethal control of carnivores compared to three non-lethal mitigation techniques over a 3-year period.

\section{Study area}

Our study took place on 11 commercial livestock farms at altitudes of 500-2,000 $\mathrm{m}$ in the Eastern Cape Province of South Africa (Fig. 1). Mean farm size was 4,291 ha (1,500$10,000 \mathrm{ha}$ ) and the farms covered a total of 47,200 ha and received annual rainfall of $230-480 \mathrm{~mm}$. During the period of the study no unusual climatic conditions were experienced. There was extensive grazing on all farms apart from Farm 2, where high-intensity, short-duration planned grazing rotation was employed (Savory, 1983). Farms were subject to varying degrees of depredation and different environmental conditions, and represented at least one of four major biomes: (1) Albany thicket, with relatively dense, woody vegetation of mean height c. 2-3 m (Mucina \& Rutherford, 2005), dominated by Portulacaria afra (spekboom) and Rhus sp.; (2) Afrotemperate forest (Mucina \& Rutherford, 2005), with yellowwood Afrocarpus falcatus and forest elder Nuxia floribunda in mountainous gorges; (3) Sandstone fynbos, which was prolific on higheraltitude farms and commonly included Protea and Erica; and (4) Nama-Karoo, which is characterized by low sweet thorn Acacia karroo in annual river beds, shrubs intermixed with grasses, and succulent plants. All farms had 


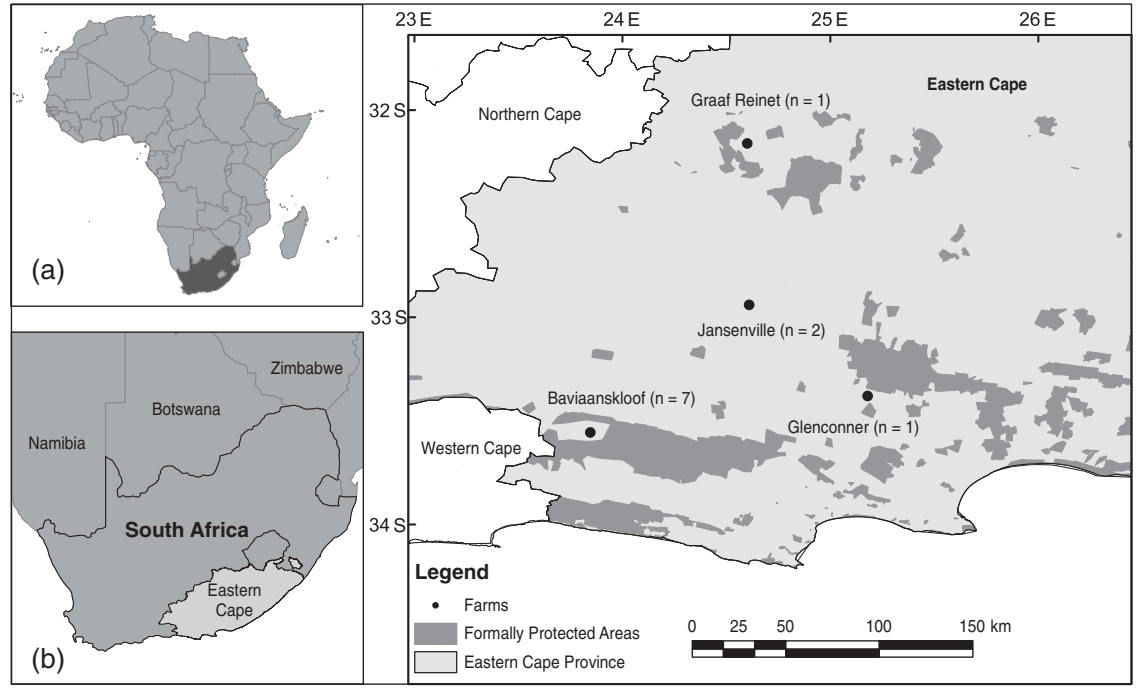

FIG. 1 The distribution and number of trial farms in the Eastern Cape Province, South Africa. The black shaded area in (a) indicates the location of South Africa, and (b) indicates the location of the Eastern Cape Province. black-backed jackal Canis mesomelas and caracal Caracal caracal present and Farms 5-11 also had leopard Panthera pardus present.

\section{Methods}

We conducted interviews with farmers from the 11 farms in September 2007, 2008 and 2009. The semi-structured questionnaire focused on farm description, quantity of livestock, number of losses and their perceived causes, depredation control methods, expenditure on control methods, and willingness to adopt non-lethal control methods. The same questionnaire was administered in person by the same researcher each year.

During the lethal-control year all farms except 1, 4 and 10 used gin-traps and hunting as their control methods. Farm 1 used gun-traps in addition to these methods, Farm 4 used only gin-traps, and Farm 10 used only hunting. During the non-lethal control years implementation and running costs (e.g. veterinary costs and food for livestock guardian animals) were sponsored for nine farms for the duration of the study, after which each farmer took responsibility for any costs. Two farms ( 2 and 4 ) chose to pay the implementation and running costs of their preferred control methods for the duration of the study and thereafter. The recruitment of farmers was facilitated by sponsorship of the controls.

The allocation of the various non-lethal controls was based on the farmers' willingness to work with livestock guardian animals, and on local conditions. To ensure accurate identification of causes of livestock losses, farmers attended training workshops and received detailed identification kits and descriptive manuals on kill identification (Smuts, 2008). When livestock was depredated, trained conservation officials and/or one of the researchers, and the farmer, undertook carcass inspections to determine if the death was caused by a predator and, if so, by which species. If there was doubt, photographs were taken and conclusions were made by external experts. Because of the size of the farms, sometimes carcasses were not discovered until it was impossible to determine the cause of death. These were excluded from analyses and cause of death was recorded as unknown.

Initial data were collected during August 2006-August 2007 (the lethal-control year) and all farms converted to non-lethal control in September 2007. Follow-up surveys were conducted at the end of September 2008 to collect data on the first non-lethal year, and at the end of September 2009 for the second non-lethal year. Therefore, the dataset for the first non-lethal year includes the initial conversion from lethal to non-lethal methods. Three farms received livestock guardian dogs (two received one dog each and the other received five), one farm received seven alpacas and the remaining seven farms received 'Dead-Stop' livestock protection collars (Klaas Louw, Cape Town, South Africa) for all stock.

Farmers received a one-off payment in the first year of implementation to cover the cost of purchasing guardian animals or collars (USD 553 per dog, USD 860 per alpaca and USD 3.50 per collar). Ongoing maintenance costs for guardian animals, such as feeding and veterinary care, averaged USD 432 per dog and USD 98 per alpaca per year. There were no running costs for collars in the first year but in the second year there was an additional replacement cost of USD 0.35 per collar for wear and tear (10\% replacement). Maintenance costs for guardian animals remained the same in the second year. If the number of livestock increased between the first and second years of non-lethal control, costs for additional collars (one per additional stock animal) were included in year two. The cost of lethal control varied according to the different methods used by farmers. The cost of tools such as gin-traps and gun-traps was calculated 
as the cost of one labourer at minimum wage (USD 8.20 per day) because legally the devices must be checked once per day and most farmers assigned one worker to check and set these devices. The cost of hunting was calculated based on daily rates charged by professional vermin hunters (USD 79) and the number of days these hunters were employed (2-12 days per year). For each individual of a target species (jackal or caracal) shot by the hunter, an additional USD 122 was charged. To standardize depredation costs, the cost of one depredated animal was calculated at USD 147.42, the mean price for a weaned lamb. We use November 2011 prices and the exchange rate at that time of ZAR 8.14 = USD 1 .

Total costs during the lethal-control year were calculated as the sum of running costs and depredation costs, in the first year of non-lethal control as the sum of implementation, running costs and depredation, and in the second non-lethal control year as running costs plus depredation. As lethal control had been used prior to the study, implementation costs for equipment such as gin-traps, gun-traps and poisons were not accounted, and therefore the overall cost of lethal control may be under-estimated. However, the running costs were considered a close representation of overall costs because items such as gintraps lasted several years and hunting was calculated as a service rather than permanent equipment. Data were not normally distributed so we represented the range of variance of the results in the data between the comparative sites. However, when comparing our results with other studies that used mean data we used means in describing the central tendency. The Wilcoxon signed-rank test for related samples was used to compare different years at the same sites and the Kruskal-Wallis $\chi^{2}$ test was used to compare continuous variables between different farms. All analyses were conducted using SPSS v. 16.o (SPSS, Chicago, USA).

\section{Results}

\section{Costs of lethal predator control and non-lethal conflict mitigation}

During the year of lethal control the cost of control measures was USD 3.30 per head of stock and the mean cost of depredation was USD 20.11 per head of stock (Supplementary Table S1). With a mean total cost of USD 23.41 per head of stock (Supplementary Table $\mathrm{S}_{1}$ ), the cost to each farmer was USD 3,552-69,290 depending on their stock holdings (mean USD 29,046). There was no significant difference in total cost per head between farms that would later receive livestock guardian dogs, alpacas or collars $\left(\chi^{2}=3.81, \mathrm{df}=2, \mathrm{P}=0.149\right)$. When implementing lethal control farmers lost $4.0-45 \%$ of their stock (mean $13.6 \%$; Supplementary Table S2) to depredation, which, given their stock holdings (Supplementary Table S1), equated to a mean cost of USD 25,306 per farm (range USD 3,392-66,340).
The mean cost of implementing non-lethal techniques was USD 2.91 per head of stock (Supplementary Table S1). During the first year of non-lethal control the mean running cost was USD 0.17 per head of stock (Supplementary Table S1), or USD 336.76 per farm (range USD 0-2,160; there were no running costs during the first year for farms using collars; Supplementary Table S1). The mean combined implementation and running cost during this year was USD 3.08 per head, similar to the running costs of lethal control $(\mathrm{Z}=-255, \mathrm{P}=0.799)$. During the same year depredation was significantly lower than when using lethal control $(\mathrm{Z}=2.93, \mathrm{P}=0.003)$. The mean decline in depredation was $69.3 \%$, with depredation accounting for $4.4 \%$ of stock (range 0.1-15.0\%; Supplementary Table S2) and costing farmers a mean of USD 6.52 per head of stock (Supplementary Table S1).

Therefore, the mean total cost per head during the first year of non-lethal control was USD 9.60 (range USD 1.49-28.82; Supplementary Table S1), significantly less (59.0\%) than the cost when using lethal control $(\mathrm{Z}=-2.85, \mathrm{P}=0.004)$. The cost decreased on 10 of the 11 farms (range 41.8-89.9\%) but on one farm (Farm 10) there was an $8.1 \%$ increase in costs relative to the lethal-control year (Supplementary Table S1). There was no significant difference in the decline in costs per head between farms using alpacas, dogs or collars $\left(\chi^{2}=4.33, \mathrm{df}=2\right.$, $\mathrm{P}=0.115)$.

The second year of non-lethal control involved no implementation costs; mean running cost was USD 0.43 per head (Supplementary Table S1). This was significantly lower than both the running costs of lethal control $(\mathrm{Z}=-2.85, \mathrm{P}=0.004)$ and the combined running and implementation costs during the first year of non-lethal control $(Z=-2.94, P=0.003)$, although the costs were significantly higher than the running costs (excluding implementation costs) of the first year of non-lethal control $\left(Z=-2.31, P=0.021\right.$; Supplementary Table $\left.S_{1}\right)$. Depredation, which accounted for $0.1-14.2 \%$ of the herd (mean 3.7\%: Supplementary Table $\mathrm{S}_{2}$ ), at a mean cost of USD 5.49 per head (Supplementary Table $\mathrm{S}_{1}$ ), declined by $72.7 \%$ compared to the lethal-control year, which is a significant difference $(Z=-2.93, P=0.003$; Supplementary Table $S_{2}$ ). Therefore, the cost of depredation declined by a mean of $15.8 \%$ compared to the first year of non-lethal control $(\mathrm{Z}=-1.79, \mathrm{P}=0.074)$, although on two farms using collars, depredation levels increased between the first and second years of non-lethal control (Supplementary Table S2). Based on stock holdings, during the second year of non-lethal control depredation declined by $73.9 \%$ compared to the lethal-control year and by $13.3 \%$ compared to the first year of non-lethal control.

The mean total cost per head of non-lethal control in the second year was USD 5.92 (range 0.72-21.62; Supplementary Table S1); this was significantly lower than the cost 
during the lethal-control year $(\mathrm{Z}=-2.93, \mathrm{P}=0.003)$. All farms reported lower total costs than during the lethal-control year, with a mean saving of $74.6 \%$ (range 54.1-95.1\%; Supplementary Table S1). Overall costs were also significantly lower than during the first year of non-lethal control on all farms $(\mathrm{Z}=-2.93, \mathrm{P}=0.003)$, with a mean decline of $43.9 \%$ (range $25.0-76.7 \%$; Supplementary Table S1). The saving per head in the second year of non-lethal control did not differ significantly between farms using different forms of control, when compared to the lethal-control year $\left(\chi^{2}=2.04, \mathrm{df}=2, \mathrm{P}=0.360\right)$ or the first year of non-lethal control $\left(\chi^{2}=2.51, \mathrm{df}=2\right.$, $\mathrm{P}=0.285$ ).

\section{Avoided depredation and profit : loss ratios in different years}

Although switching from lethal to non-lethal control resulted in significant declines in both depredation and total costs, this does not fully reflect the economic savings that were made. The non-lethal measures led to considerable cost savings through avoided depredation, assuming that depredation would have remained at the same level as under lethal control. Implementing non-lethal control saved farmers a mean of USD 13.58 per head of stock in avoided depredation (Supplementary Table $S_{3}$ ), which equates to a saving of USD 20,384 per farmer, based on the mean herd size of 1,501 in the first year of non-lethal control. Combined with a saving on running costs of USD 0.21 per head of stock (Supplementary Table $S_{3}$ ), the overall saving compared to what would have been expected under lethal control was USD 13.79 per head, a mean saving of USD 20,699 per farmer. Given the total cost of implementation, running expenses and depredation during the first year, this gives a mean profit:loss ratio of $2.11: 1$, with all but one farmer showing a profit (Supplementary Table $S_{3}$ ). Where the running cost of lethal control was cheaper than that of non-lethal techniques, the lower-than-expected depredation still resulted in a profit (Supplementary Table $S_{3}$ ). There was no significant difference in the profit:loss ratio between different forms of non-lethal control $\left(\chi^{2}=1.82, \mathrm{df}=2\right.$, $\mathrm{P}=0.403)$.

In the second year of non-lethal control, farmers saved a mean of USD 17.41 per head of stock (range USD 3.29-47.67; Supplementary Table $S_{3}$ ) compared to what would have been expected under lethal control. All farms had a positive profit: loss ratio compared to lethal control, saving a mean of USD 5.36 for every USD 1 spent (range USD 1.16-18.11; Supplementary Table $S_{3}$ ). As in the first year of non-lethal control, there was no difference in the mean profit:loss ratio between farms using different non-lethal methods $\left(\chi^{2}=2.04, \mathrm{df}=2, \mathrm{P}=0.360\right)$.

Comparing the 2 years of non-lethal control, two farms (18\%) experienced higher levels of depredation in the second year and nine (82\%) experienced slightly lower depredation (Supplementary Table $\mathrm{S}_{2}$ ). Compared to the first year of non-lethal control, these changes amounted to a profit : loss ratio of 1.23:1 (Supplementary Table $S_{3}$ ). This ratio did not differ significantly according to the non-lethal method implemented $\left(\chi^{2}=0.90, \mathrm{df}=2, \mathrm{P}=0.637\right)$.

\section{Post-trial follow ups}

Observations made 13 months after the study finished revealed that $55 \%$ of the farms continued to use non-lethal control. All farms with livestock guardian animals (Farms 1-4) retained them at their own expense, two others ( 6 and 11) acquired livestock guardian animals in addition to existing methods, and one (Farm 10) only retained the collars. Just under half the farms (45\%) combined both lethal and non-lethal methods after cessation of the trial; Farms 5, 7, 8 and 9 used both hunters and collars and Farm 3 used gin-traps, hunting dogs, hunting and collars.

After 30 months $36 \%$ of farms (2, 4, 8 and 10) used only non-lethal control, $46 \%(1,3,5,6$ and 11$)$ combined lethal and non-lethal control, and $18 \%$ (7 and 9) used only lethal control. Depredation was reported to have remained the same by $30 \%$ of farms (4, 5 and 8$), 30 \%$ reported an increase in depredation ( 7,9 and 11$)$ and $40 \%$ reported a decrease $(1,2,3$ and 10) since the end of the trial. This information was not available for Farm 6 because livestock farming was only reinstated 1 month prior to the interview. Six farms used livestock guardian animals (1-4, 6 and 11) but the dog on Farm 1 was shot by a neighbour who feared it would cause damage to livestock. The farmer did not replace the dog but instead placed lambing ewes in fenced camps to avoid losses at vulnerable times. Farms 3 and 4 made no changes to management and Farms 6 and 11 stopped farming livestock 19 months after the trial ceased, until April 2013 and December 2012, respectively. When livestock farming was re-established Farm 6 re-acquired a livestock guardian dog and Farm 11 used shepherds and electrified lambing camps. Farms 7 and 9 used only lethal controls. Farm 9 reported that it was easier to implement because it was managed by a neighbour; Farm 7 undertook calland-shoot hunting over several farms to reduce predator numbers and avoid losses. Farm 8 used three livestock guardian dogs and Farm 10 used shepherds in mountainous areas. All farms except Farm 7 remained willing to pay for non-lethal controls; Farm 7 indicated that payment to use non-lethal control would increase the likelihood of its use.

\section{Discussion}

Large carnivores are often highly valued at a global scale but have a low or negative economic value at a local scale 
(Dickman et al., 2011). To address this, local revenue from carnivore presence should outweigh the costs of coexistence. This can be achieved by generating more local revenue, for instance through tourism or payments for presence (Sillero-Zubiri et al., 2004; Dickman et al., 2011), and also by reducing the costs incurred locally as a result of carnivore presence. Our findings suggest that non-lethal mitigation can effectively reduce depredation and the economic costs of carnivores in the vicinity of livestock farming. Farmers saved 55.1 and $74.6 \%$ during the first and second years of non-lethal control, respectively, compared to expected losses during lethal control. Even where lethal controls were cheaper to implement than non-lethal methods, the lower-than-expected depredation resulted in savings in both years when non-lethal controls were used. There was a mean saving of USD 13.79 per head of stock in the first year of non-lethal control and USD 17.41 per head in the second, compared to what would be expected when using lethal control only. Overall, farmers saved a mean of $>$ USD 20,000 during the first year of switching to non-lethal measures, which was equivalent to the value of 138 livestock. Initiating and operating non-lethal control during the first year was cheaper than continuing lethal control on the majority of study farms, and depredation rates were invariably lower. In short, non-lethal measures were cheaper than lethal control on $91 \%$ of the farms in the first year of implementation. On the one farm where the implementation costs were lower for lethal control, only low-intensity control was employed (Supplementary Table $S_{1}$ ). In the second year, depredation remained low, running costs were minimal and all farms reported lower costs per head than under lethal control. The economic case for non-lethal approaches is further strengthened if the avoided losses from depredation under lethal control are considered. This made non-lethal predator control twice as lucrative during the first year and $>5$ times so during the second year.

Large-scale, intensive and expensive lethal-control experiments have resulted in a $51-68 \%$ reduction in depredation rate (Guthery \& Beasom, 1978; O'Gara et al., 1983; Wagner \& Conover, 1999; Greentree et al., 2000). This benefit is similar to, or less than, the 69.3 and $73.9 \%$ reduction we found during the first and second years of implementing non-lethal measures. Given the higher cost of lethal control, this suggests that non-lethal measures are a more economical option.

We are mindful that the design of our study lacked a formal control, as there was no sample of farms in the second and third years on which lethal control continued for comparison. Nonetheless, the reductions in cost and depredation were similar across all farms (irrespective of locations, biomes and environmental conditions). We do not have grounds to believe that the reduction in depredation that occurred during non-lethal control would have occurred without our experimental intervention, or that such a reduction occurred on comparable farms that continued to use lethal control. Farms neighbouring the study farms may have increased the intensity of their predator control but we have no evidence for this and it seems unlikely that this would have happened across all the disparate locations. Furthermore, seven of the experimental farms (Farms 5-11) were adjacent to protected areas, where there would have been no scope, legally, for control of predators; the remaining four had neighbours that practised lethal control. Some other confounding factor, such as infectious disease, could have reduced predator populations during the second and third years of our trial on all sampled farms but there was no evidence for this and it is unlikely to have occurred at all of the different sites. Farmers may have exaggerated reported losses during the first year of the survey to demonstrate their need for help, thereby distorting our findings, but this is unlikely to have occurred in every case. Although other studies have identified a positive correlation between carnivore absence and human presence (Ogada et al., 2003; Bunnefeld et al., 2006) there is no evidence that local human activity was substantially higher in the years when non-lethal control was implemented. Another possibility is that experimental cessation of lethal controls somehow diminished losses of non-target species, and consequently natural prey numbers increased more than the target predators, relieving the pressure on domestic stock. Although none of these potential explanations appears to be likely, we suggest that future studies are run with control sites and non-lethal trials concurrently for longer periods, to determine if and when predators either adapt to non-lethal measures (Brand et al., 1995) or repopulate to a level at which the control measures become ineffective (Gese, 2005), and whether depredation and costs of control remain low in the long term. Understanding the effect of lethal controls on non-target species population densities could help to determine whether changes occur in their availability and frequency and whether this could affect depredation on livestock.

Although, under the particular circumstances of our trial, non-lethal methods yielded significant cost-savings, using lethal control is not purely an economic decision. Hunting of carnivores is often culturally and socially embedded and may provide intangible benefits such as social prestige and enjoyment (Hazzah et al., 2009; Marchini \& Macdonald, 2012). It is likely that many farmers will want to continue some form of carnivore hunting but if nonlethal methods continue to be effective it will be clear that this is driven more by cultural norms and satisfaction than economics. Furthermore, the adoption of non-lethal methods will depend on the local context; for example in many areas livestock-keepers may not have the means or the inclination to invest time, care and resources in livestock guardian dogs or exotic animals such as alpacas. 
Determining the most appropriate methods for the local socio-economic and cultural environment is a vital step in encouraging farmers to adopt novel forms of non-lethal control. According to our interviews all 11 farmers were willing to pay for non-lethal control if it effectively reduced losses. However, 9 of the 11 farms were provided with such controls free of charge, which probably accelerated the rate of uptake, and two farmers bought and implemented the controls without financial support. Therefore, although many farmers may be willing to implement non-lethal controls they may not do so without incentives or support of some kind. However, attitudes towards predators are rarely based on economics alone but are influenced by a variety of personal factors, including beliefs and values, education, upbringing, tradition and culture (Zimmermann et al., 2005).

Our observations indicate that after non-lethal controls are introduced, in most cases (82\%) their use is continued or alternative non-lethal methods are tried, either in isolation or alongside lethal controls. Depredation increased on the two farms where only lethal controls were used and decreased on $50 \%$ of farms where only non-lethal methods were implemented. On the other $50 \%$ there was no change in the level of depredation. Where lethal and non-lethal controls were combined, losses to depredation decreased on $50 \%$ of farms, remained the same on $25 \%$ of farms and increased on the remaining $25 \%$. Given that depredation increased when using lethal controls, it seems that the use of such controls is influenced by the attitudes of farmers and their neighbours as much as by any realized economic advantages.

Further and long-term controlled trials are needed to investigate whether the benefits we observed as a result of non-lethal controls are sustainable. Such trials could also evaluate predator habituation to non-lethal techniques and the effectiveness of methods such as using alpacas to guard against larger predators such as leopards. Our results suggest that non-lethal forms of livestock protection, whether livestock guardian animals or barriers such as collars, can efficiently and cost-effectively reduce depredation on domestic stock. These methods reduced the economic cost of livestock depredation by carnivores for at least 2 years, which is important for improving the local cost: benefit ratio of carnivore presence. They may also benefit conservation by reducing the motivation for retaliatory or pre-emptive killing of carnivores, and by reducing the effects of control on non-target species. The use of non-lethal conflict mitigation approaches may also be useful in reducing edge effects (Woodroffe \& Ginsberg, 1998) on species and provide safety buffer zones adjacent to protected areas or along important wildlife corridors. Since this study was completed there has been a strong uptake in the use of various livestock protective collars, including in Iran.

\section{Acknowledgements}

We are grateful to the private landowners who willingly participated in this trial of non-lethal predator control and agreed to forgo the use of lethal controls for the duration of the study, many of whom have continued to use non-lethal controls following the trial. We thank Sandra Baker, Paul Johnson, Gus Mills, Jan Kamler and Alan Lee for insightful comments, and the ABAX Foundation (previously the Polaris Foundation), Pick'n Pay, Woolworths, the Henry and Iris Englund Foundation, the National Lotteries Distribution Trust Fund, Arne Hanson, the Mones Michaels Trust and Royal Canin for sponsoring the tools to undertake this research. A Wits-Carnegie fellowship provided support to JM during the final preparation of the article, AD is a Kaplan Senior Research Fellow at Pembroke College, Oxford, and DWM warmly acknowledges the support of the Recanati-Kaplan Foundation, the Peoples' Trust for Endangered Species and the Swift family.

\section{References}

Andelt, W.F. \& Hopper, S.N. (2000) Livestock guard dogs reduce predation on domestic sheep in Colorado. Journal of Range Management, 53, 259-267.

Atkinson, R.P.D. \& Macdonald, D.W. (1994) Can repellents function as a nonlethal means of controlling moles (Talpa-Europaea)? Journal of Applied Ecology, 31, 731-736.

Avenant, N.L. \& DU Plessis, J.J. (2008) Sustainable small stock farming and ecosystem conservation in Southern Africa: a role for small mammals? Mammalia, 72, 258-263.

Baker, S.E., Ellwood, S.A., Slater, D., Watkins, R.W. \& Macdonald, D.W. (2008) Learned food aversion plus odour cue protects crop from mammalian wildlife foraging. The Journal of Wildlife Management, 72, 785-791.

Bamford, A.J., Diekmann, M., Monadjem, A. \& Mendelsohn, J. (2007) Ranging behaviour of Cape Vultures Gyps coprotheres from an endangered population in Namibia. Bird Conservation International, 17, 331-339.

BEASOM, S. L. (1974) Selectivity of predator control techniques in South Texas. The Journal of Wildlife Management, 38 , $837-844$.

Beinart, W. (2008) The Rise of Conservation in South Africa: Settlers, Livestock, and the Environment 1770-1950. Oxford University Press, Oxford, UK.

Berger, K.M. (2006) Carnivore-livestock conflicts: effects of subsidized predator control and economic correlates on the sheep industry. Conservation Biology, 20, 751-761.

Bradley, E.H., Pletscher, D.H., Bangs, E.E., Kunkel, K.E., Smith, D.W., MAck, C.M. et al. (2005) Evaluating wolf translocation as a nonlethal method to reduce livestock conflicts in the northwestern United States. Conservation Biology, 19, 1498-1508.

Brand, D.J., Fairall, N. \& Scott, W.M. (1995) The influence of regular removal of black-backed jackals on the efficiency of coyote getters. South African Journal of Wildlife Research, $25,44-48$.

Breitenmoser, C., Angst, U., Landry, C., BreitenmoserWürsten, C., Linnell, J.D.C. \& Weber, J.M. (2005) Non-lethal techniques for reducing depredation. In People 
and Wildlife: Conflict or Coexistence? (eds R. Woodroffe, S. Thirgood \& A. Rabinowitz), pp. 49-71. Cambridge University Press, Cambridge, UK.

Bunnefeld, N., Linnell, J.D.C., Odden, J., Van Duijn, M.A.J., \& ANdersen, R. (2006) Risk taking by Eurasian lynx (Lynx lynx) in a human-dominated landscape: effects of sex and reproductive status. Journal of Zoology, 270, 31-39.

Conner, M.M., Ebinger, M.R., Knowlton, F.F. (2008) Evaluating coyote management strategies using a spatially explicit, individualbased, socially structured population model. Ecological Modelling, 219, 234-247.

Conover, M. (2001) Effect of hunting and trapping on wildlife damage. Wildlife Society Bulletin, 29, 521-532.

Coppinger, R., Coppinger, L., Langeloh, G., Gettler, L. \& Lorenz, J. (1988) A decade of use of livestock guarding dogs. Proceedings of the Thirteenth Vertebrate Pest Conference, 13, 209-214.

Cox, R., Baker, S.E., Macdonald, D.W. \& Berdoy, M. (2004) Protecting egg prey from carrion crows: the potential of aversive conditioning. Applied Animal Behaviour Science, 87, 325-342.

Croокs, K.R. \& Soulé, M.E. (1999) Mesopredator release and avifaunal extinctions in a fragmented system. Nature, 400, 563-566.

Daly, B., Davies-Mostert, H., Davies-Mostert, W., Evans, S., Friedmann, Y., King, N. et al. (eds) (2006) Proceedings of a Workshop on Holistic Management of Human-Wildife Conflict in the Agricultural Sector of South Africa. Endangered Wildlife Trust, Johannesburg, South Africa.

Davidison-Nelson, S.J. \& Gehring, T.M. (2010) Testing fladry as a nonlethal management tool for wolves and coyotes in Michigan. Human-Wildlife Interactions, 4, 87-94.

Dickman, A.J., Macdonald, E.A. \& Macdonald, D.W. (2011) A review of financial instruments to pay for predator conservation and encourage human-carnivore coexistence. Proceedings of the National Academy of Sciences of the United States of America, 108, 13937-13944.

Gehring, T.M., VerCauteren, K.C. \& Landry, J.M. (2010) Livestock protection dogs in the 21st century: is an ancient tool relevant to modern conservation challenges? BioScience, 60, 299-308.

GeSE, E. (2005) Demographic and spatial responses of coyotes to changes in food and exploitation. Proceedings of the Wildlife Damage Management Conference, 11, 271-285.

Graham, K., Beckerman, A.P. \& Thirgood, S. (2005) Human-predator-prey conflicts: ecological correlates, prey losses and patterns of management. Biological Conservation, 122, 159-171.

Green, J.S., Woodruff, R.A. \& Tueller, T.T. (1984) Livestockguarding dogs for predator control: costs, benefits, and practicality. Wildlife Society Bulletin, 12, 44-50.

Greentree, C., Saunders, G., McLeod, L. \& Hone, J. (2000) Lamb predation and fox control in south-eastern Australia. Journal of Applied Ecology, 37, 935-943.

Guthery, F.S. \& BeAsom, S.L. (1978) Effects of predator control on Angora goat survival in South Texas. Journal of Range Management, $31,168-173$.

Hazzah, L., Borgerhoff Mulder, M. \& Frank, L. (2009) Lions and warriors: social factors underlying declining African lion populations and the effect of incentive-based management in Kenya. Biological Conservation, 142, 2428-2437.

Holmern, T., Nyahongo, J. \& Roskaft, E. (2007) Livestock loss caused by predators outside the Serengeti National Park, Tanzania. Biological Conservation, 135, 518-526.

Hone, J. (1994) Analysis of Vertebrate Pest Control. Cambridge University Press, New York, USA.
Knowlton, F.F., Gese, E.M. \& Jaeger, M.M. (1999) Coyote depredation control: an interface between biology and management. Journal of Range Management, 52, 398-412.

KRUUK, H. (2002) Hunter and Hunted: Relationships between Carnivores and People. Cambridge University Press, Cambridge, UK.

Linhart, S.B., Sterner, R.T., Carrigan, T.C. \& Henne, D.R. (1979) Komondor guard dogs reduce sheep losses to coyotes: a preliminary evaluation. Journal of Range Management, $32,238-241$.

Loveridge, A.J., Wang, S.W., Frank, L.G. \& Seidensticker, J. (2010) People and wild felids: conservation of cats and management of conflicts. In Biology and Conservation of Wild Felids (eds D.W. Macdonald \& A.J. Loveridge), pp. 161-195. Oxford University Press, Oxford, UK.

MacDonald, D.W. \& BAKER, S.E. (2004) Non-lethal control of fox predation: the potential of generalised aversion. Animal Welfare, $13,77-85$.

Macdonald, D.W., Boitani, L., Dinerstein, E., Fritz, H. \& Wrangham, R. (2013) Conserving large mammals: are they a special case? In Key Topics in Conservation Biology 2 (eds D.W. Macdonald \& K.J. Willis), pp. 277-312. Wiley-Blackwell, Oxford, UK.

Macdonald, D.W., Loveridge, A.J. \& Rabinowitz, A. (2010) Felid futures: crossing disciplines, borders and generations. In Biology and Conservation of Wild Felids (eds D.W. Macdonald \& A.J. Loveridge), pp. 599-649. Oxford University Press, Oxford, UK.

Marchini, S. \& Macdonald, D.W. (2012) Predicting ranchers' intention to kill jaguars: case studies in Amazonia and Pantanal. Biological Conservation, 147, 213-221.

Marker, L.L., Dickman, A.J. \& Macdonald, D.W. (2005) Perceived effectiveness of livestock-guarding dogs placed on Namibian farms. Rangeland Ecology \& Management, 58, 329-336.

Marker, L., Dickman, A., Mills, G. \& Macdonald, D.W. (2010) Cheetahs and ranchers in Namibia: a case study. In Biology and Conservation of Wild Felids (eds D.W. Macdonald \& A.J. Loveridge), pp. 353-372. Oxford University Press, Oxford, UK.

Mason, J.R., Shivik, J.A. \& FALl, M.W. (2001) Chemical repellents and other aversive strategies in predation management. Endangered Species Update, 18, 175-181.

Mitchell, B.R., Jaeger, M.M. \& Barrett, R.H. (2004) Coyote depredation management: current methods and research needs. Wildlife Society Bulletin, 32, 1209-1218.

Mucina, L. \& Rutherford, M.C. (eds) (2005) The Vegetation of South Africa, Lesotho and Swaziland. South African National Biodiversity Institute, Pretoria, South Africa.

Ogada, M.O., Woodroffe, R., Oguge, N.O. \& Frank, L.G. (2003) Limiting depredation by African carnivores: the role of livestock husbandry. Conservation Biology, 17, 1521-1530.

O'Gara, B.W., Brawley, K.C., Munoz, J.R. \& Henne, D.R. (1983) Predation on domestic sheep on a western Montana ranch. Wildlife Society Bulletin, 11, 253-264.

Ray, J., Hunter, L. \& Zigouris, J. (2005) Setting Conservation and Research Priorities for Larger African Carnivores. Wildlife Conservation Society, New York, USA.

Reynolds, J.C. (1999) The potential for exploiting conditioned taste aversion (CTA) in wildlife management. In Advances in Vertebrate Pest Management (eds D.P. Cowan \& C.J. Feare), pp. 267-82. Filander Verlag, Fürth, Germany.

Rochlitz, I., Pearce, G.P. \& Broom, D.M. (2010) The Impact of Snares on Animal Welfare. Cambridge University Press, Cambridge, UK. 
SAvory, A. (1983) The Savory grazing method or holistic resource management. Rangelands, 5, 155-159.

Schiess-Meier, M., Ramsauer, S., Gabanapelo, T. \& König, B. (2007) Livestock predation-insights from problem animal control registers in Botswana. The Journal of Wildlife Management, $71,1267-1274$.

SHIVIK, J.A. (2006) Tools for the edge: what's new for conserving carnivores. BioScience, 56, 253-259.

Sillero-Zubiri, C. \& Laurenson, M.K. (2001) Interactions between carnivores and local communities: conflict or co-existence? In Carnivore Conservation (eds J.L. Gittleman, S.M. Funk, D.W. Macdonald \& R.K. Wayne), pp. 282-312. Cambridge University Press, Cambridge, UK.

Sillero-Zubiri, C., Reynolds, J. \& Novaro, A.J. (2004) Management and control of wild canids alongside people. In Biology and Conservation of Wild Canids (eds D.W. Macdonald \& C. Sillero-Zubiri), pp. 123-142. Oxford University Press, New York, USA.

Smuts, B. (2008) Predators on Livestock Farms: A Practical Farmers' Manual for Non-lethal, Holistic, Ecologically Acceptable and Ethical Management. Landmark Foundation, Riversdale, South Africa. Http://www.landmarkfoundation.org.za/uploads/5/ 9/0/1/5901915/predators_on_livestock_farms_a_practical_manual_ for_non_lethal_holistic_ecologically_acceptable_and_ethical_ management_landmark_foundation.pdf [accessed 6 March 2014].

Statistics South Africa (2010) Census of Commercial Agriculture 2007. Report No. 11-02-01 (2007). Statistics South Africa, Pretoria, South Africa.

Treves, A. \& Karanth, K.U. (2003) Human-carnivore conflict and perspectives on carnivore management worldwide. Conservation Biology, 17, 1491-1499.

Treves, A. \& Naughton-Treves, L. (2005) Evaluating lethal control in the management of human-wildlife conflict. In People and Wildlife: Conflict or Coexistence? (eds R. Woodroffe, S. Thirgood \& A. Rabinowitz), pp. 86-106. Cambridge University Press, Cambridge, UK.

Tuyttens, F.A.M. \& Macdonald, D.W. (2000) Consequences of social perturbation for wildlife management and conservation. In Behaviour and Conservation (eds L.M. Gosling \&
W.J. Sutherland), pp. 315-329. Cambridge University Press, Cambridge, UK.

VAN NIEKERK, H.N. (2010) The cost of predation on small livestock in South Africa by medium sized predators. MSc thesis. Free State University, Bloemfontein, South Africa.

Wagner, K.K. \& Conover, M.R. (1999) Effect of preventive coyote hunting on sheep losses to coyote predation. The Journal of Wildlife Management, 63, 606-612.

WANG, S.W. \& MACDONALD, D.W. (2006) Livestock predation by carnivores in Jigme Singye Wangchuck National Park, Bhutan. Biological Conservation, 129, 558-565.

Woodroffe, R. \& Ginsberg, J.R. (1998) Edge effects and the extinction of populations inside protected areas. Science, 280, 2126-2128.

Woodroffe, R., Thirgood, S. \& Rabinowitz, A. (2005) The impact of human-wildlife conflict on natural systems. In People and Wildlife: Conflict or Coexistence? (eds R. Woodroffe, S. Thirgood \& A. Rabinowitz), pp. 1-12. Cambridge University Press, Cambridge, UK.

Zimmermann, A., Walpole, M. J. \& Leader-Williams, N. (2005) Cattle ranchers' attitudes to conflicts with jaguar Panthera onca in the Pantanal of Brazil. Oryx, 39, 406-412.

\section{Biographical sketches}

Jeannine McManus has experience in restoring wildlife habitat and addressing the conflict caused by economic losses to the livestock industry as a result of carnivore predation. AMY DICKMAN has been researching human-carnivore conflict in Africa for 15 years, with a particular focus on testing the efficacy of non-lethal conflict mitigation techniques. DAVID GAYNOR is a specialist in mammal behaviour ecology and is also a livestock farmer. B O O L SM U T s has been involved in human-wildlife conflict mitigation efforts since 2004. He develops projects integrating environmental ethics, viable economics and social responsibility. DAVID MACDONALD's research interests lie in the behavioural ecology of carnivores, especially with relevance to human-carnivore conflict. He has studied large felids in Africa, Asia and South America. 